\title{
Rock Crusher Upgrade Business from a PLM Perspective
}

\author{
Simo-Pekka Leino, Susanna Aromaa and Kaj Helin
}

\begin{abstract}
Global trends of ecology and sustainable development, safety awareness, changing legislation, and urbanization, together with the economic situation, force industry to find solutions for extending product lifecycles, while maintaining and improving machine system performance and other properties during the lifecycles. Together with these societal issues, firms are struggling with competitiveness. This chapter introduces the new Use-it-Wisely (UIW) approach to upgrading rock crushers at customer sites. The higher level problem needing to be solved concerned making upgrade delivery projects profitable and more desirable for customers, manufacturing OEMs and suppliers. The main recognized and treated bottlenecks were related to knowing the actual status of the upgrade target, communication and collaboration with stakeholders, verification and validation of upgrade specifications and an efficient information flow between the stakeholders. Augmented reality (AR), Virtual environments (VE), camera based 3D scanning, and cloud based solutions are the selected pieces of technology for solving the bottlenecks. They enable better communication, collaboration and involvement of all stakeholders, including customers, internal stakeholders, suppliers and partners. They also better enable the planning and discussing of service quality activities. Product life-cycle management (PLM) is the framework for developing and managing product related information, processes and collaboration expanding towards product middle-of-life, end-of-life, and service lifecycle management. This study is a proof-of-concept that demonstrates the potential of contributions to business model innovations and game changes for upgrading business.
\end{abstract}

\footnotetext{
S.-P. Leino $(\bowtie) \cdot S$. Aromaa $\cdot$ K. Helin

VTT Technical Research Centre of Finland Ltd., Espoo, Finland e-mail: simo-pekka.leino@vtt.fi

S. Aromaa

e-mail: susanna.aromaa@vtt.fi

K. Helin

e-mail: kaj.helin@vtt.fi

(C) The Author(s) 2017

S.N. Grösser et al. (eds.), Dynamics of Long-Life Assets,

DOI 10.1007/978-3-319-45438-2_12
} 
Keywords Technological support of collaboration - Upgrading of assets • Business model innovation - Product life cycle management - Mining and construction

\section{Introduction}

This chapter introduces how novel digital technology may enable an innovative new business model for upgrading old machines, in the mining and construction industry. Global trends of ecology and sustainable development, safety awareness, changing legislation, and urbanization, together with the economic situation, are forcing development of solutions for extending product lifecycles, while maintaining and improving machine system performance and other properties during the lifecycles. Together with these societal issues, firms are struggling with competitiveness. Often, they optimize short-term financial performance, while missing the most important customer needs and ignoring the broader influences that determine their long-term success (Porter and Kramer 2011). A true understanding of customer and user needs, and the needs of society, in general, is often missing. Simultaneously, core competences and key assets, such as knowledge and skills of employees and partners are underrated.

However, the most enlightened manufacturing firms are seeking new business and revenues from services and maintenance, such as the upgrading of older machine individuals. However, service design raises new challenges, compared to traditional product design engineering. Compared to physical products, services are generally under-designed and inefficiently developed (Cavalieri and Pezzotta 2012). This problem is the focus of Product-Service System (PSS) research. On the other hand, Product Lifecycle Management (PLM) is a strategic approach, where business is seen from a product perspective covering product related information, processes and collaboration. Thus, PLM should be a framework, where PSS and service products are developed and managed. However, conventional views of PLM tend to stress the design, engineering and production phases, while the use and end of life phases are, typically, not very well covered (Wuest 2015). This is the challenge of the case company, as well. It faces the problems of maximizing customer value and societal satisfaction, while increasing their own profitability. The principle of "shared value" (Porter and Kramer 2011) is proposed as a solution for creating economic value in a way that also creates value for society, by addressing its needs and challenges.

\subsection{The Industrial Case}

The industrial case relates to equipment manufacturing and services for the mining and construction sectors. Two companies, an original equipment manufacturer 
$(\mathrm{OEM})$ and a research and development $(\mathrm{R} \& \mathrm{D})$ partner in upgrade services, were involved in the case study. The OEM case company, a manufacturer of rock crushers wants to serve their customers by providing machine upgrade solutions that support machine utilization and the customers' capability for crushing rocks, for instance, near urban areas, by decreasing the noise and dust levels of the machines. This is challenging, because every partially configurable machine individual is different when it leaves the factory and it is often modified by the customer or a third party during its lifecycle. The lifecycle may exceed ten years and, during that time, machine deformations typically occur, due to harsh conditions. Therefore, it is difficult to know the status of the machines at the customer sites, around the world. Thus, machine upgrade projects are, generally, not very attractive or profitable. The major high level business questions are:

- How to make upgrade business profitable

- How to establish a successful business model for rock crushing machine upgrades

- How to effectively manage upgrade service projects?

\subsection{Product Life Perspective and Product Life-Cycle Approach}

Having a long tradition (Wuest 2015) in both engineering and management science, Product Life-cycle Management (PLM) proposes to help with the challenges of maintaining the performance of existing products and developing new competitive products for changing and turbulent business environments. Fast reactions to these changing markets and customer requirements, as well as the involvement of stakeholders, requires a sound information basis, which, in manufacturing, could be provided by PLM (Wiesner et al. 2015). Besides product and process related data, PLM also takes into account the interdependencies of information and communication between all of the stakeholders involved in the product lifecycle (Wuest 2015).

PLM originates from Product Data Management (PDM) with its original focus on design engineering data for Computer Aided Design and Computer Aided Engineering (CAD/CAE) (Wiesner et al. 2015); however, PLM increasingly focuses on the whole product lifecycle (both the product types and product individuals) and promises to manage all involved data and information (Wuest 2015). While the initial objectives of PDM were to improve product quality and reduce costs, additional objectives also became important (Wiesner et al. 2015): time reduction, streamlining of processes, increased value for the customer and innovation. Thus, newer PLM approaches are aligned to changes in market conditions and technical opportunities (Wiesner et al. 2015). 
In PLM, life phases of products can roughly be divided (Wiesner et al. 2015) into the Beginning of Life (BoL), the Middle of Life (MoL), and the End of Life (EoL). This view is different from marketing, where a product life is divided into five phases: introduction, growth, maturity, saturation and degeneration (Wuest 2015). To elaborate, the three phases of product life in PLM are (Wiesner et al. 2015):

- BoL: The product is imagined as an idea in the minds of the designers, which are then converted into a detailed product specification, in the definition stage. During the realization phase, the product is manufactured and delivered to the customer.

- MoL: The product is in the possession of the customer, who uses it for their applications. The product is also supported by the manufacturer, in order to maintain its functionalities.

- EoL: The product loses its usefulness for its intended purpose. It is retired or upgraded by the manufacturer or disposed of by the customer for eventual reuse or recycling.

By definition, PLM takes a holistic view to product life, taking into account both the lifecycles of product types and families, as well as product individuals. However, as previously stated, the focus of PLM has been more on the beginning of life than on the middle or end of life phases. Newer proposed approaches such as "Closed-loop PLM" (Jun et al. 2007), take an even greater holistic view upon of the entire product lifecycle, which, ideally, also includes the end of one lifecycle merging into the beginning of the next (Wuest 2015). The concept of a closed loop PLM provides the opportunity to maximize the benefits of the lifecycle operations. This raises the importance of knowing what the whole product lifecycle activities consist of, how its information is created, used, and modified during the product lifecycle, and which lifecycle information affects the product lifecycle operation (Jun et al. 2007). The aim of a closed-loop PLM is to close the information gaps between the different phases and processes of the product lifecycle of individual products, both backwards and forwards (Wuest 2015). Recent PLM approaches also consider product related service in the lifecycle of products (Wiesner et al. 2015). However, closed-loop PLM and service requires dealing with products as item-level individuals, which is still a common challenge (Wuest 2015). In other words, manufacturing companies that want to develop and offer service products, e.g. product upgrades, often do not know the exact status of product individuals at their customer sites. The common question is how product individual level upgrades and service products can be supported in PLM?

\subsection{Tool Selection}

The main industrial problem treated in this chapter concerns making upgrade services profitable and establishing a business model to support that goal. This chapter covers the biggest bottlenecks. These are: 
- Knowing the actual status of the upgrade target, thus getting initial data and information for an upgrade delivery project

- Global communication with customers in the field, to form a true understanding of their needs and possible limitations

- Validation of customer requirements, to ensure that the needs are understood and correctly specified

- Management of upgrade service products and offerings

- Support of engineering design of upgrades, taking into account the limitations

- Collaboration and communication between the upgrade stakeholders

- Validation of the proposed upgrade solution with the customer

- Efficient information flow during delivery of the upgrade project.

As previously stated, PLM, for the case company, is the framework of developing and managing product related information, processes and collaboration. On the other hand, PLM as a theoretical concept as well as from an industrial implementation viewpoint, is just expanding to cover a product's middle-of-life, end-of-life, and service lifecycle management. The above listed bottlenecks are, at the same time, common PLM research targets and problems related to the case companies' upgrade service business. PLM is about creating, using, modifying, and managing product and service related information, for all stakeholders. In this case, information related problems are more specifically related to issues in Table 1.

The preliminary and principle selection of the proposed tools and solutions for the above described bottlenecks and the PLM information related problems are partly based on previous experiences with certain tools and techniques, and partly on a collaboration with other Clusters and partners, in the Use-it-Wisely (UIW) EU-project. The proposed main solutions to the problems and expected advantages are listed in Table 1.

Table 1 PLM related challenges of rock crusher upgrading and proposed solutions

\begin{tabular}{l|l|l}
\hline PLM related challenge & $\begin{array}{l}\text { Proposed } \\
\text { solution }\end{array}$ & Expected advantage \\
\hline $\begin{array}{l}\text { Creating digital data and information } \\
\text { about the target machine, including } \\
\text { 3D geometry }\end{array}$ & $\begin{array}{l}\text { 3D scanning } \\
\text { (3D data } \\
\text { capture) }\end{array}$ & $\begin{array}{l}\text { Fast and cost-efficient way to get the } \\
\text { actual status and geometry }\end{array}$ \\
\hline $\begin{array}{l}\text { Visualization of upgrade service } \\
\text { offerings and proposed solutions for } \\
\text { customers }\end{array}$ & $\begin{array}{l}\text { Augmented } \\
\text { Reality (AR) } \\
\text { Virtual } \\
\text { Environments } \\
\text { (VE) }\end{array}$ & $\begin{array}{l}\text { Mobile and cheap solution for } \\
\text { operations in field } \\
\text { Possibility to test non-existing } \\
\text { solutions and environments }\end{array}$ \\
\hline $\begin{array}{l}\text { Visualization of the target machine } \\
\text { status and boundary conditions for } \\
\text { engineering designers }\end{array}$ & $\begin{array}{l}\text { Virtual } \\
\text { Environments } \\
\text { (VE) }\end{array}$ & $\begin{array}{l}\text { Possibility to test non-existing } \\
\text { solutions and environments } \\
\text { Effective way to share information } \\
\text { and knowledge }\end{array}$ \\
\hline $\begin{array}{l}\text { Keeping digital data and information } \\
\text { up-to-date and sharing it in an } \\
\text { appropriate format, for all required } \\
\text { stakeholders }\end{array}$ & $\begin{array}{l}\text { Cloud-based } \\
\text { PLM module }\end{array}$ & $\begin{array}{l}\text { Possibility to automate information } \\
\text { management and dynamically } \\
\text { involve different stakeholders }\end{array}$ \\
\hline
\end{tabular}


Two major principles in proposing and selecting tools and solutions for the described problems are: (1) To utilize "COTS" Commercial Off-The-Shelf solutions and (2) the possibility to integrate them into company processes and information management systems, so that they benefit business. Different versions of the selected technologies are tested and developed from the perspective of functionality, user acceptance and business process benefit.

Finally, data processing and information flow between the applications that support the upgrade sales-delivery process is established, based on cloud technology and a product lifecycle management system. Modular and configurable upgrade solutions enable information re-use and an effective engineering design phase of the project.

Utilization of techniques and methodologies, such as VE and AR in this case context, can be put under the umbrella of "virtual prototyping", which is defined by (Wang, 2002) as follows: "Virtual prototype, or digital mock-up, is a computer simulation of a physical product that can be presented, analyzed, and tested from concerned product life-cycle aspects such as design/engineering, manufacturing, service, and recycling as if on a real physical model. The construction and testing of a virtual prototype is called virtual prototyping (VP)". When virtual prototyping is considered from an engineering design and product development viewpoint, taking into account product information management and the whole product lifecycle, it should be connected with PLM development. In (Leino 2015) the theory and practice of virtual environments, based on virtual prototyping in product development and product lifecycle management, is discussed. Furthermore, (Ovtcharova 2010) provides a practical outline of the process definition and IT-system environment of "virtual engineering", and (Bordegoni et al. 2009) introduces a mixed prototyping approach and framework for product assessment. They see it as a practice for effective and rapid design reviews and validation of new products from an ergonomic and usability perspective. Engineering design reviews (see e.g. Huet et al. 2007) are one of the most important application areas of virtual prototyping. However, the majority of the published virtual prototyping examples are related to new product development, which is not really the case, in this research. The important question is: how to mix the virtual and physical worlds of existing and to-be-defined objects?

\subsection{State-of-the-Art of the Proposed Technical Solutions}

Augmented (Mixed) Reality (AR) was proposed as a means of improving the customer interface, including visualization of upgrade offerings, as well as validation of upgrade solutions. It was also intended to assist service and maintenance workers in the field, for instance, in assembling the upgrade solution on top of an old machine. Augmented (Mixed) Reality involves the superposition of computer graphics over real objects or scenes (Shen et al. 2010). Compared with VR, AR is a semi-immersive design environment in which the users can see the real world, 
while performing feature modelling, on a virtual product. Recent industrial applications of AR include, for instance, collaborative product design and development (Shen et al. 2010), design reviews (Verlinden et al. 2009), development and planning of complex production processes and systems (Dangelmaier et al. 2005) and architectural and Construction Site Visualization (Woodward and Hakkarainen 2011). AR helps the understanding of project documentation (Meža et al. 2015) and enables graphical highlighting of an interesting phenomenon already in the design phase, thus, determining problems and risks, sooner (Tuma et al. 2014).

Virtual Environments (VE) were recognized as a medium for collaborative engineering design and as a communication medium between the upgrade service stakeholders, including the customers and partners in the supply network. Virtual Environments can be defined as "interactive, virtual image displays enhanced by special processing and by nonvisual display modalities, such as auditory and haptic, to convince users that they are immersed in a synthetic space." (Ellis 1994). However, VE have presented challenges to human-computer interaction (Wilson and D'Cruz 2006). Research with VE started in the 1960s, with NASA being one of the pioneer institutes. However, after several decades, the technical and methodological development of VE is now becoming mature enough for real and serious utilization in industry. VE is currently reliving a renaissance.

VE for virtual prototyping of assembly and maintenance verifications has already been introduced by Gomes de Sá and Zachmann (1998). They saw it as a very promising technology, but they also state that it would not become a wide-spread tool before being integrated with IT infrastructure. One of the recent studies related to the design review of complex industrial assemblies was introduced by Di Gironimo et al. (2014). They have already solved many of the product information management challenges specifically related to VE and PDM interfaces. Other manual assembly and maintenance related VE research were reported, for example, by Chryssolouris et al. (2000) and Gomes de Sá and Zachmann (1999).

3D scanning was proposed as a piece of technology that enables efficient initial data gathering (i.e. 3D geometry) at the customer site. 3D scanning is a technology that analyses real-world objects and environments in order to gather data on shape and appearance. From the data, three dimensional models of reality can be constructed. In principle, there exist two commercially available methods on the market: (1) active (e.g. laser, sonar) and (2) passive (e.g. photogrammetric scanning using mobile digital cameras). There are many recent examples of the use of different 3D scanning technologies in industry and civil engineering. The approach of Erdos et al. (2014) on retrofitting complex engineering objects, such as factories and utilization computer aided design, is similar to ours; however, their paper is more focused on the technical development of 3D scanning devices. Bosche and Haas (2008) report technical 3D scanning advancements in the architectural and construction sectors as do (Bi and Wang 2010) in manufacturing. Many of the recent technical developments are related to 3D scanning with portable devices, such as smartphones, tablets and PDAs. Examples of such research are reported, e.g. by Ancona et al. (2015), Kolev et al. (2014), Tanskanen et al. (2013). 
3D laser scanning and point cloud based applications are used, for instance, in the renewal of electrical substations, when the original CAD models are outdated (Gonzalez-Aguilera et al. 2012), which is also similar to our approach. Kumar et al. (2012) have utilized point clouds in reverse-engineering and they introduced a detailed methodology of scanning and applications. Berglund et al. (2014) have reported how 3D laser scanning enables the capturing of spatial digitized data, quickly, in order to support discrete event simulations of production systems. This integration of point cloud data, with simulations, is supposed to enable better decision-making (Berglund et al. 2013). It is also based on the created realistic visualization and better common understanding of the redesigned production systems (Lindskog et al. 2014). Based on the experiences of (Weidlich et al. 2009), 3D laser scanning can enhance the creation of virtual test scenarios related to optimization and extension of existing environments.

\subsection{Outline of This Chapter}

The rest of this chapter is organized as follows: The next section introduces more detail on how the technical solutions were applied, what they are, and how they were tested and evaluated. Furthermore, the next section describes the conceptual definition of the new product upgrade service model. First, the as-is situation and requirements analysis are explained.

After that, in the Discussion section, the benefits and limitations of selected and developed technical solutions are reported and discussed compared to the requirements and situation before the projects, as well as compared to other published research. Also discussed are what implications can be drawn from this research for PLM development and implementation. Finally, concluding remarks are made on benefits and further challenges.

\section{Tool Applications and Solution to the Company Challenges}

The major business problems are:

- How to make upgrade business profitable

- How to establish a successful business model for rock crushing machine upgrades

- How to manage upgrade service projects efficiently.

These questions were approached by modelling the as-is situation in the case companies, discussing it with the product stakeholders and recognizing the most remarkable bottlenecks of the machine upgrade projects. These included 
communication channels on the customer interface, validation of the problem definition with the customer, getting the initial data for the project, effectively designing an upgrade solution, verification of the solution and validation with the customer and end user. The business cases were created with the requirement of cheap and easy to use technology that can be integrated with business solutions.

Figure 1 illustrates the complex network of internal and external product upgrade stakeholders, and their concerns. The rich picture shows how society and authorities put into place regulations and ethical demands for the end-customers of the OEM manufacturing company concerning, for instance, noise and dust levels near urban areas. These demands originate with the end-customer and end-users and go to the OEM. For example, if end-users need to decrease the noise levels of their rock crushing machines, they may ask the OEM to upgrade the machine to fulfil the noise level requirements of the authorities. The OEM wants to serve the end-customer as well as possible, while simultaneously trying to keep their business profitable. They need to effectively manage the end-customer interface as well as their internal and external upgrade delivery processes. Previously, these processes have not been optimal, causing productivity challenges.

As was described in the Introduction section, AR, VE and 3D scanning were proposed as technical tools in order to meet the business goals of upgrading old rock crushing machines at customer sites. Cloud solutions and PLM system configurations were adopted to support the required information management processes. The following section introduces evaluation of the proposed technical applications.

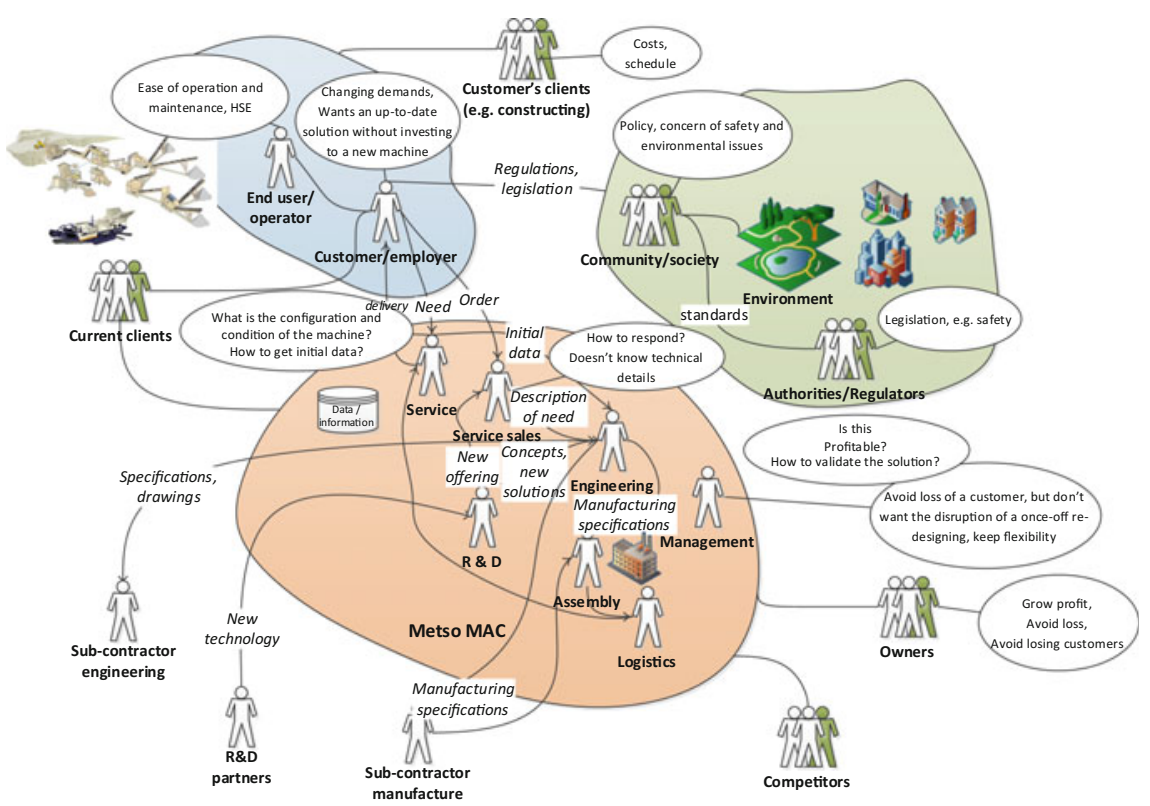

Fig. 1 Rich Picture model describing the complexity of an as-is situation between stakeholders 


\subsection{Trials and Demonstrations}

The tools and solutions to enable an innovative new business model for upgrading old machines were tested and developed during three trials and a demonstration period. This section introduces a summary of the goals, methods and results of the trials and demonstrations.

\subsubsection{Trial 1: Evaluation of the Proposed Business Model}

Goal: The objective in Trial 1 was to discuss and evaluate a new proposed business model and preliminary ideas concerning new upgrade delivery processes and tools. The new business model should provide the possibility to design, configure and customize upgrades for the customers, machines, based on a catalogue of upgrades, with the support of advanced tools and solutions, which would help to reduce cost and delivery time. The aim was to improve profitability and systematize work.

Material and method: A process diagram ("Swim-Lane") was made from the proposed business model. It described a hypothetical sales-delivery process within the new business model in which organizational functions and/or networked companies are involved. The process diagram was evaluated by using a walk-through method in a focus group session.

Results: The new proposed business model received common acceptance from the focus group. However, the main discussion continued to be on current business challenges. Therefore, the summarized main challenges in the current upgrade process, were as follows:

1. Presently there is no clear upgrade process

2. Sometimes it is difficult to prepare a reliable and fast offer for a client after specific requests are made for an upgrade

3. Documentation needs to be improved for better information sharing

4. An easier and faster process for collecting initial data for upgrade projects is needed.

\subsubsection{Trial 2: Evaluation of 3D Capture Technology}

Goal: The objective in Trial 2 was to test and evaluate different 3D scanning systems and the usefulness of produced 3D data, for upgrade design in Virtual Environments and in engineering/design application such as CAD/CAE.

Materials and method: During the test, data was collected and three different 3D scanning systems were compared. These systems included one laser scanning and two different systems for 3D reconstruction from multiple camera images. There were three different cases: 
1. A mobile rock crushing unit of the OEM

2. A commercial component-gear box

3. Production line- jaw crusher assembly line.

Two different 3D scanning techniques were tested: (1) laser (active) and (2) photogrammetric (passive) mobile digital camera (still and video) based. Figures 2 and 3 are from the first tests of camera based scanning.

Results: 3D scanning seemed to be a very useful technology. However, based on these tests, the data pipeline from the scanned raw data to CAD/CAE or VE software was only working properly in the photogrammetrically generated $3 \mathrm{D}$ models. This scanning accuracy is not always suitable for detailed design, but can be applied to concept design and discussing the boundary conditions for the design. The accuracy of laser scanning is probably also suitable for detailed design, however, the data import to the CAD and VR software did not yet work properly, with the given pieces of technology. Table 2 explains the evaluated advantages and disadvantages of the two 3D scanning methods.

For instance, (Golparvar-Fard et al. 2011) have also compared two 3D scanning methods, camera based and 3D laser scanning, in modelling the as-built status of a construction site. They concluded that camera based methods are less accurate, but that both methods are capable of producing 3D representations for visualizing the environment, from different viewpoints.
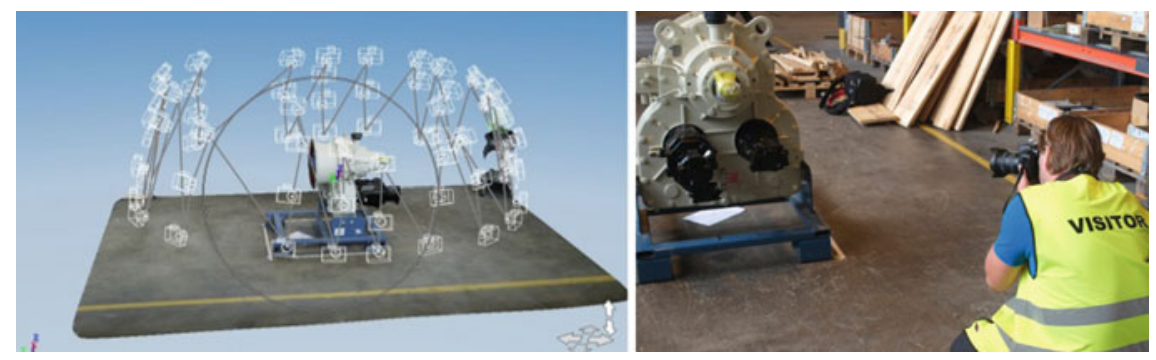

Fig. 2 In the Trial 2 Camera based photogrammetric 3D capture was applied in scanning a gear box at the OEM factory
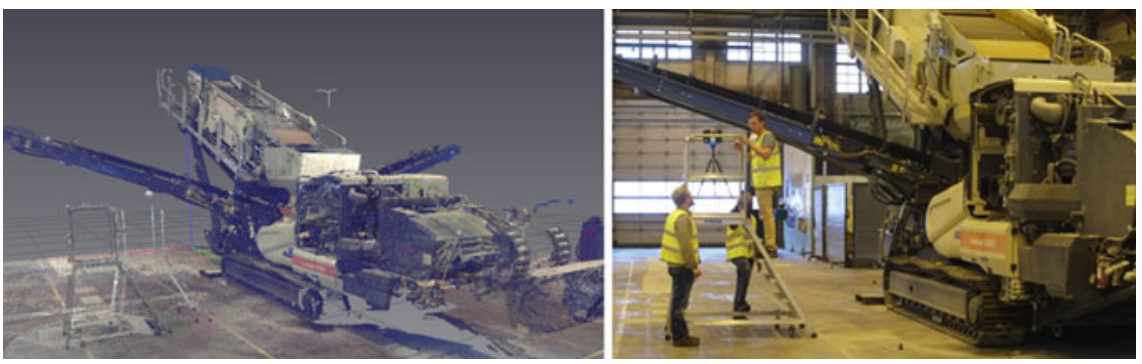

Fig. 3 Laser scanning and generated point cloud representation 


\subsubsection{Trial 3: Evaluation of Digital Visualization Technology}

Goal: The goal of Trial 3 was to evaluate two different 3D visualization systems, during an upgrade design. AR and VE systems were tested to support design reviews.

Materials and methods: The design object, reviewed in the test, was a machine maintenance platform attached to a mobile rock crushing machine. This was an upgrade module for an existing machine. The purpose of the maintenance platform was to provide a safe, ergonomic and efficient workspace for maintenance workers. In the AR test, the system included a virtual model of the upgrade module (the maintenance platform), the real rock crushing machine, a virtual frame and a cover, a real environment, three different postures of a digital human model (DHM) and a human participant. In the VE test system, the model included a virtual model of the product (the maintenance platform), a virtual model of the rock crushing machine, a virtual environment, three different postures of a DHM, a human participant and 3D models of hands and shoes. Nine people from the OEM company participated in the $\mathrm{AR}$ test and ten people from the company participated in the VE test. Questionnaires and interviews were used as data collection methods. Figure 4

Table 2 Advantages and disadvantages of 3D laser scanning and camera based 3D capture

\begin{tabular}{l|l|l}
\hline Method & Advantages & Disadvantages \\
\hline $\begin{array}{l}\text { 3D laser } \\
\text { scanning }\end{array}$ & $\begin{array}{l}\text { Accuracy } \\
\text { Speed }\end{array}$ & $\begin{array}{l}\text { Not portable } \\
\text { Requires special training } \\
\text { Limited and/or laborious possibility to generate 3D } \\
\text { models for VE and CAD/CAE }\end{array}$ \\
\hline $\begin{array}{l}\text { Camera } \\
\text { based }\end{array}$ & $\begin{array}{l}\text { Can be used with a } \\
\text { normal smartphone } \\
\text { Easy-to-use } \\
\text { Relatively inexpensive }\end{array}$ & $\begin{array}{l}\text { Limited accuracy } \\
\text { Model quality depends on user skills } \\
\text { Sensitive to light conditions }\end{array}$ \\
\hline
\end{tabular}
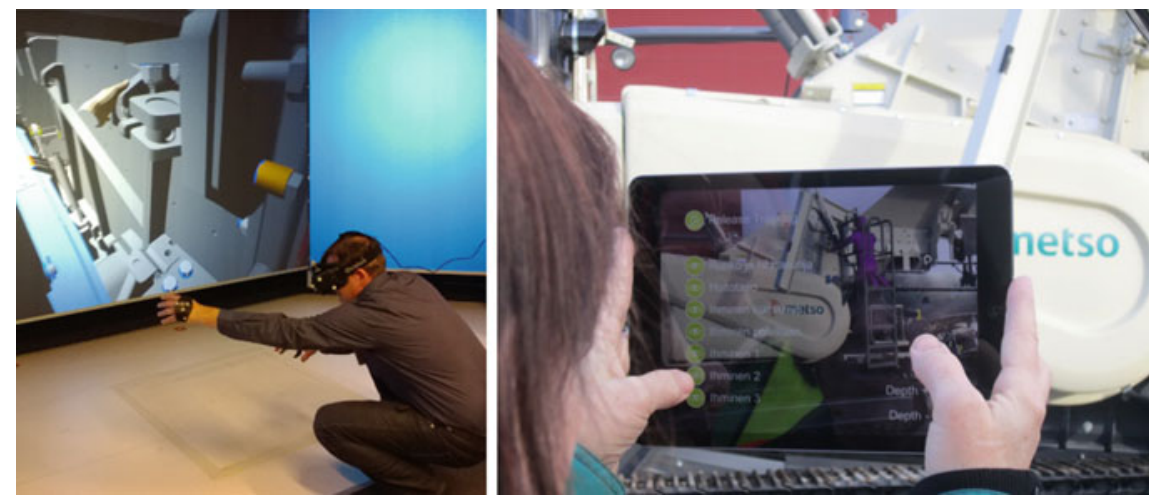

Fig. 4 Upgrade design review in a VE (left) and upgrade validation with an AR application (right) 
shows the testing of the VE with the upgrade design engineer (left), and the testing of the upgrade visualization AR application, with an end user.

Results indicate that both of the AR and VE prototypes were suitable for assessment of certain human factor/ergonomic (HFE) related issues (Aromaa and Väänänen 2016). AR-systems could be particularly valuable for illustrating upgrade solutions to the upgrade stakeholders (marketing, customers and assembly workers) in the field. The VE prototype was more comprehensive and immersive for the designers, when reviewing the HFE issues of the upgrade machine.

In addition, data sharing was tested. Data sharing was tested by means of the RD Cloud $^{\mathrm{TM}}$ platform. It allowed the 3D scanned data (point clouds, polygon models and design models related to photos and video) to be stored in the cloud, as well as the data collected from the AR-system. The users were able to understand and appreciate the potential of the tool, but it needs greater customization, according to the users' needs (i.e. show photos preview, allow CAD data conversion in other formats, enhance the uploading feature, etc.).

The demonstration phase was aimed at proving the technical maturity, usability and usefulness from the viewpoints of end users, customers and other stakeholders, as well as to demonstrate the big picture (capability from upgrade delivery process and data management viewpoints) and business impact potential. The three demonstration cases, and their evaluation criteria, are listed in Table 3.

Figure 5 shows how the new pieces of technology should contribute to the upgrade delivery projects. Previously, there were no process or method definitions

Table 3 Demonstration cases and their evaluation criteria

\begin{tabular}{l|l|l}
\hline$\#$ & Demonstration case & Evaluation criteria \\
\hline 1 & $\begin{array}{l}\text { Smartphone, video based, 3D-scanning and } \\
\text { automatic 3D model creation. Data } \\
\text { collection for upgrades with collaboration } \\
\text { with engineering service provider }\end{array}$ & $\begin{array}{l}\text { Anyone should be able to use a smartphone } \\
\text { for scanning (no restrictive requirements on } \\
\text { how to record the video) } \\
\text { The quality of the pictures, the transfer } \\
\text { speed and the quality of the created 3D } \\
\text { model } \\
\text { Also the usability and the overall workload } \\
\text { and time of this scanning method }\end{array}$ \\
\hline $\mathbf{2}$ & $\begin{array}{l}\text { Noise encapsulation demonstration for a } \\
\text { customer (or sales personnel) with AR and } \\
\text { VR. Review a large scale machine upgrade } \\
\text { with a customer, verify key customer } \\
\text { requirements, such as maintainability, } \\
\text { transportability etc. }\end{array}$ & $\begin{array}{l}\text { User experience, interviews and monitoring } \\
\text { (end-customer, serviceman, designer) }\end{array}$ \\
\hline $\mathbf{3}$ & $\begin{array}{l}\text { Dust suppression or safety upgrade } \\
\text { installation (combination of Cases \#1 and } \\
\text { \#2). Review a minor/mid-size machine } \\
\text { upgrade with engineering and customer }\end{array}$ & $\begin{array}{l}\text { Get initial data from existing products (3D } \\
\text { scanning with video) } \\
\text { Check the upgrade installation in 3D CAD, } \\
\text { with a scanned model } \\
\text { Also check with a virtual model and AR } \\
\text { Data pipeline } \\
\text { Interview test users (assembly workers, } \\
\text { designers, servicemen, sales, customer) }\end{array}$ \\
\hline
\end{tabular}




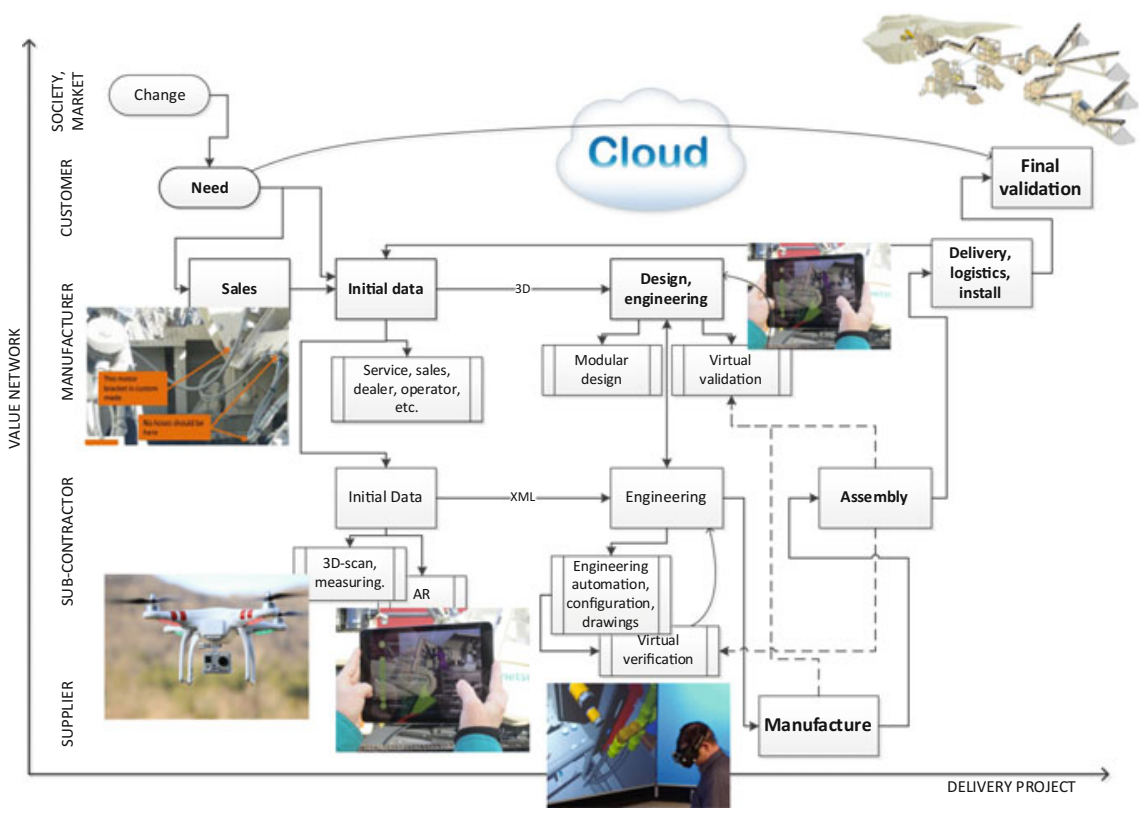

Fig. 5 The new innovative rock crusher upgrade delivery process that exploits 3D capture, AR/VE and Cloud

for old machine upgrade projects. It has been more of an ad hoc activity, as described in Fig. 1. Product processes of the OEM company have been optimized for configuring and producing new machine variants, and the upgrade projects have been disturbing this day-to-day business. Moreover, it has had a narrow perspective without taking into consideration the roles of partners, suppliers and customers. Firstly, the UIW-approach made these processes and roles explicit, taking into account the whole chain, from customer needs to upgrade deliveries. Secondly, in the UIW-approach, the aforementioned pieces of technology enable the retrieval of information on the initial situation at a customer site, collaborative design and verification and validation of the upgrade solutions (Fig. 5). Cloud solutions enable information flow and processing.

\section{Discussion}

The main high level industrial problems touched in this chapter was about making upgrade services profitable and establishing a business model to support that goal. However, this chapter does not describe a business model; neither does it show quantitative evidence about increased profitability. Nevertheless, this chapter does discuss how future novel pieces of technology may change upgrade project 
processes and remove current major process bottlenecks that hinder profitability. There is no quantitative data supporting the claimed productivity increase. Instead, productivity is claimed to be increased by better effectivity, more value adding work and less waste in the upgrade processes. This was preliminary assessed by using as-is and to-be process models and simulation games. The main bottlenecks of upgrade service profitability are related to knowing the actual status of the upgrade target, communication and collaboration with stakeholders such as customers, engineers, service personnel and supply networks, as well as effective tool, method and information management, during an upgrade delivery project. Thus, optimal support for the design process requires integrated 3D digitalization and a multidisciplinary approach in order to solve the complex problems (Weidlich et al. 2009).

The new approach is based on clever engineering design solutions for the upgrade products, as well as on the digitalization of information flows of the upgrade projects. Clever engineering design solutions mean modularized upgrade products and services that can be configured, at least partially, for a specific customer need. Thus, less engineering work from scratch is needed. Digitalization of information flows means, of course, that information is in digital format, but also that it flows through an upgrade service project smoothly. It means that the data and information are correct, up-to-date and available for all stakeholders, when needed. This is the task of PLM. PLM should support (Jun et al. 2007): Management of lifecycle objects, collaboration between customers, partners and suppliers, and the firm's ability to analyse challenges and make decisions on them. In most cases, it is necessary to share product information with several suppliers and partners.

Digitalization saves a lot of calendar time and unproductive work, but it also makes information content richer. When, for instance, a realistic digital 3D model of the upgrade target is instantly available to designers, they can begin the definition upgrade solution immediately, with more reliable initial data. Furthermore, additional information about the upgrade target status can be attached to the model. This means making information content rich, which is also the task of PLM. Productivity increases by decreasing unproductive work during an upgrade delivery project. When information is correct and available, there is less need for searching and rework due to wrong status information and corrections. The status information can be discussed among all stakeholders and decisions can be made based on better quality information. For instance, 3D laser scanned models can increase understanding and bridge the gap between different areas of expertise (Lindskog et al. 2013).

Requirement specifications of the upgrade can be validated with the customer and the proposed upgrade solutions can be verified against the requirements and validated with the customer, based on virtual models. Virtual design reviews allow multiple designers and other stakeholder to highlight possible design flaws and make choices in real time (Di Gironimo et al. 2014). When design flaws are recognized earlier, with a virtual prototype model, and engineering changes are made based on them, there is a potential for decreasing changes with manufactured physical products. 
Furthermore, AR- and VE-based visualization enables better understanding of information, and thus, better communication and involvement of the stakeholders. People with different backgrounds and prior knowledge can create similar mental models, which enables better discussion and decision making (Lindskog et al. 2013; Leino 2015). Virtual models enable stakeholders that are unexperienced with CAD to work with virtual prototypes (Gomes de Sá and Zachmann 1999). Additionally, the stakeholders can virtually test and train the use of the products, before they exist, which can lead to improved usability and ergonomics (Ottosson 2002).

Therefore, more knowledge is involved in the process, which decreases uncertainty and improves the quality of decision making. The changing market situation and customer needs can be responded to with better knowledge management, leading to new product-service innovations. VE based virtual prototyping does have the potential to improve overall product quality, especially for those business processes where humans play an important role (Gomes de Sá and Zachmann 1999). Therefore, the potential business impact of VE is also manifested though a more holistic view of the PSS, rather than just a component or product centric view (Ovtcharova 2010).

\subsection{Product Lifecycle Management Perspective}

There is an industrial need to have easy access to product use phase (MoL) information, in order to better provide a value adding combination of products and services for customers (Lejon and Jeppsson 2015). On the other hand, manufacturing companies still have a traditional engineering approach to the tangible part of engineering and leave the intangible service element to intuitive processes and methods (Cavalieri and Pezzotta 2012). The shift from traditional product centric product development to PSS development is an opportunity to create radical innovations (McAloone and Andreasen 2004), but it requires an increased awareness of complex lifecycle issues, including variance of stakeholders and societal issues. Cavalieri and Pezzotta have discussed using virtual environments for interaction between service providers and clients and visualizing new service concepts. A similar approach is part of our UIW-concept, as well. Virtual environments and virtual prototyping enables extending the virtual phase of the product lifecycle towards service planning and management, thus integrating traditional PLM and SLM (Service Lifecycle Management).

However, from a PLM perspective, a sound methodology to combine product lifecycle and service lifecycle does not exist. Therefore, challenges remain for closing feedback loops from, for example, the service delivery to the BoL phase of products (Wiesner et al. 2015). The closed-loop PLM approach intends to close these loops and emerging new technologies enable the gathering and analysing of product lifecycle information and decision making, without spatial and temporal constraints (Jun et al. 2007). In recent papers, e.g. (Lejon and Jeppsson 2015) feedback loops are closed using advanced sensor technology that records the events 
and status of the technical product, itself. Thus, our UIW-approach contributes to the closed-loop PLM and service lifecycle management by providing an approach that utilizes AR, VE and 3D scanning for gathering and analysing product lifecycle information.

The main phases of product life are the beginning of life (BoL), the middle of life $(\mathrm{MoL})$, and the end of life (EoL). In the closed-loop PLM, designers and production engineers receive feedback information from distributors, maintenance/ service, customers, re-manufacturers, etc. This information, from the MoL and the EoL, can also be indirectly used for the design and production of the next generation products (Jun et al. 2007). Traditionally, this kind of product individual status information is lacking in product design and development, but the closed-loop PLM aims to enable it in successful business operations. Thus, our UIW-approach contributes to closing two information loops in product life:

1. Upgrading a product individual at a customer site

2. Bringing the product $\mathrm{MoL}$ and EoL knowledge to a new product and service design and development.

The Closed-loop PLM can have direct and indirect loops of information flows over an extended product lifecycle, meaning that a lot of product lifecycle information can be accumulated and used, not only in the current lifecycle, but also with the next (Jun et al. 2007). Our UIW-approach enables the gathering of the digital status data and information, such as a 3D model of an item-level product individual and information about its use and circumstances, at the customer site. This approach can contribute to the concept of Product Avatars (Wiesner et al. 2015), where the idea is to create virtual, item-level, product individual models, where product lifecycle information is linked. It encompasses philosophical ideas similar to that of the German "Industry4.0" concept (see e.g. Brettel et al. 2014), where production systems and product individuals should have virtual twins. Our 3D approach enables both the effective design and development of an upgrade delivery PSS through the virtualization of the product and the related work tasks. Furthermore, it enables the taking of product $\mathrm{MoL}$ and EoL information into account, when designing and developing new generation products and services (Fig. 6).

\subsection{Tool Use Limitations}

Relatively new pieces of technology have been developed and tested as part of the UIW-product-service upgrade approach. They have not really been implemented into business processes; this study has been more of a proof-of-concept. The technology maturity, usability and benefits have been evaluated against business cases in order to assess the realistic potential in creating new value and innovative upgrade business. Here, it is important to understand that value cannot be purely measured quantitatively in money, but rather that value is created in more fluent 


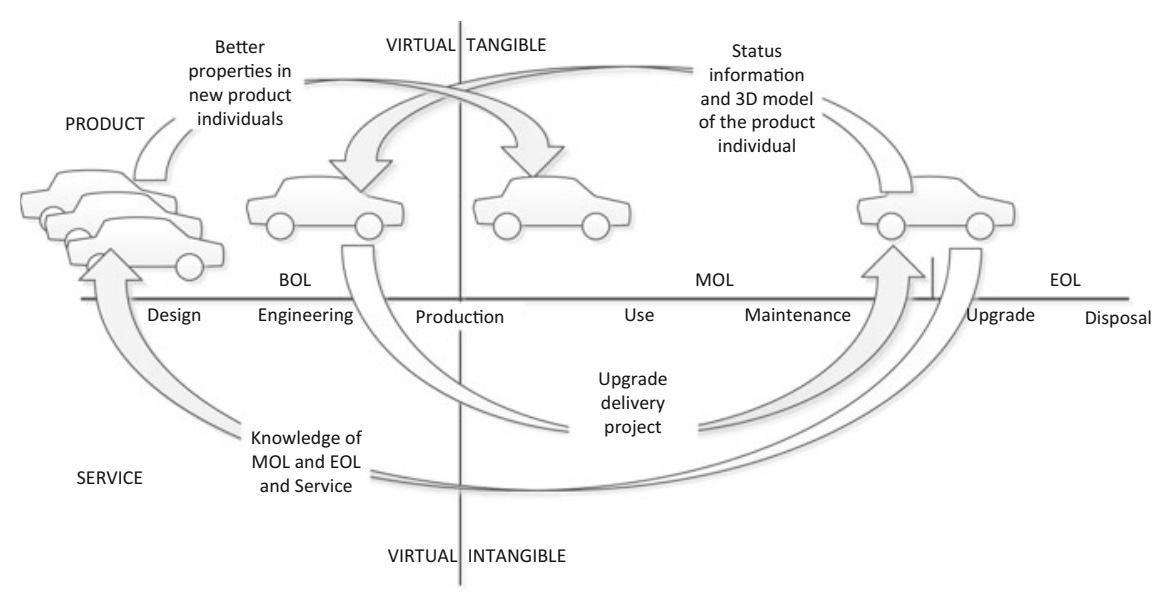

Fig. 6 Closing knowledge loops of product lifecycle by virtualisation product representations

processes, such as customer satisfaction and quality. On the other hand, if we consider the impacts on productivity (Tangen 2005), we need to distinguish between efficiency (doing things right), effectivity (doing the right things) and usability. Previously, it was claimed, that our UIW-approach increases productivity by decreasing the amount of waste, such as searching for information and unnecessary rework. This can only be evaluated by looking at the impact at the business success level. The difference between evaluating the usability and efficiency of a certain tool, such as an AR device, and the effectivity on a business process level, can be described with the distal/proximal evaluation model (Blessing and Chakrabarti 2009). What clearly increases productivity, where the total upgrade process is concerned, is the use of digital models created in VE as instruction material in AR (Damgrave et al. 2014).

The limitations of the present VE system result in an inability to test all aspects of design, which often leads to only emphasizing the testable aspects (Damgrave et al. 2014). Virtual prototyping, which is also VE and AR based, has been commonly claimed to shorten product development lead times and increase flexibility. However, the above mentioned problem, of the possibility to simulate all aspects of design, may lead to a situation of "pseudoflexibility" (Damgrave et al. 2014).

So far, in the UIW-project, it has not been possible to see the actual distal impacts, i.e. business benefits. However, the tested tools and methodology seem very promising. Considering the rapid technological progress, it is safe to say that it may be a potential game changer in upgrading business.

However, there is a "Virtual prototyping paradox" (Leino 2015) involving the difference between the claimed benefits and the expectations related to VE and virtual prototyping, and the actual industrial implementations and evidence for business advantages. On the one hand, this may be caused by the ambiguous definition of virtual prototyping. It seems to be useful for practically everything, but 
this broad applicability can also be a source of difficulty (Ellis 1994). Thus, the barriers of implementing VE and other such technology are not only caused by costs of equipment, but also by the knowledge of how to work with it (Ottosson 2002). Without seamless integration with a firm's processes, information management and way of working, this technology will not create the potential value. In all likelihood, both the new tool and existing processes, as well as the fundamental way of thinking, will require adjustment in order to create the maximum value (Damgrave et al. 2014). Without making clear connections with the input and output of other process and project phases, there is a risk that VE will just be handled as a tool, separate from the product processes.

From the technology perspective, the described UIW-approach includes AR, VE, camera based 3D scanning, as well as cloud and PLM solutions. They were tested and proven to have great potential for making product-service upgrade business more profitable. Affordable technology, such as mobile phones can already be used for 3D scanning and AR-applications. Some researchers (Meža et al. 2015) also see the potential of, such things as AR applications, but they are sceptical as to the possibility of replacing the conventional product information presentation techniques. Concerning virtual assembly simulations, (Chryssolouris et al. 2000) state that despite the time technical level and realism of VE, its feasibility and usefulness was demonstrated, especially when taking into account human involvement, in the process.

However, there are still some limitations (Table 4) related to technical maturity and user friendliness of $\mathrm{AR} / \mathrm{VE}$ and 3D-scanning. The human factors of these technologies are also critical and they are dealt with, e.g., in the paper of (Wilson and D'Cruz 2006). Most of the current VE applications still require a high level of craftsmanship to achieve the potential advantages, and the applications are often built for a dedicated process or project (Damgrave et al. 2014). According to

Table 4 Limitations and anticipated near future improvements of the used technology

\begin{tabular}{l|l|l}
\hline Piece of technology & Current limitations & Near future improvements \\
\hline Augmented Reality (AR) & $\begin{array}{l}\text { Data pipeline } \\
\text { Integration with PLM } \\
\text { Often requires tailoring } \\
\text { Technical problems, } \\
\text { such as stability of } \\
\text { images }\end{array}$ & $\begin{array}{l}\text { Standardization of data formats and } \\
\text { information models } \\
\text { Growing market will foster SW and } \\
\text { HW development of COTS }\end{array}$ \\
\hline $\begin{array}{l}\text { Virtual Environments } \\
\text { (VE) }\end{array}$ & $\begin{array}{l}\text { Needs an expert operator } \\
\text { Integration with PLM }\end{array}$ & $\begin{array}{l}\text { VE will be integrated with PLM and } \\
\text { CAE } \\
\text { Standardization of data formats and } \\
\text { information models }\end{array}$ \\
\hline 3D scanning & $\begin{array}{l}\text { Accuracy } \\
\text { Usability }\end{array}$ & $\begin{array}{l}\text { Growing market will foster SW and } \\
\text { HW development of mobile devices }\end{array}$ \\
\hline $\begin{array}{l}\text { Product Lifecycle } \\
\text { Management (PLM) and } \\
\text { Cloud }\end{array}$ & Information models & $\begin{array}{l}\text { New PLM models including MoL, } \\
\text { EoL and service } \\
\text { Standardization of data formats and } \\
\text { information models }\end{array}$ \\
\hline
\end{tabular}


Damgrave et al., one reason for this is a lack of standardization, but so is the ignorance of technology developers in regard to available possibilities and real user needs. However, technology is progressing fast and this is the right time for establishing prerequisites for digitalization of machine upgrade processes.

\section{Conclusion}

This chapter has introduced the UIW-approach to upgrading rock crushers at customer sites. The high level business problem to be solved concerned making upgrade delivery projects profitable and more desirable for customers, manufacturing OEMs and suppliers. The main recognized and treated bottlenecks were related to knowing the actual status of the upgrade target, communication and collaboration with stakeholders, verification and validation of upgrade specifications, and an efficient information flow between the stakeholders.

AR, VE, camera based 3D scanning, and cloud based solutions were selected in order to solve the bottlenecks. One principle in the selection was to use commercial off-the-shelf (COTS) tools, as much as possible. Laser based 3D scanning (active) was also tested and compared with camera based photogrammetric scanning (passive). The accuracy of laser scanning was better, but camera based was chosen because of its mobility and ease of use. Nowadays, almost everyone carries a smartphone, which makes camera-based 3D scanning attractive. 3D scanning enables fast and cost efficient acquisition of the actual 3D model of the product individuals, at customer sites. VE is a means to visualize scan based 3D models, as well as CAD based 3D models, so that all stakeholders can better understand them. This enables better communication, collaboration and involvement of all stakeholders, including customers, internal stakeholders, suppliers and partners. With the use of VE and AR, it is possible to illustrate upgrade offerings for customers and to test proposed solutions, virtually. They also enable the planning and discussing of service activities. The proposed solutions can be verified and validated, before building physical products. VE/AR and PLM based solutions enable more fluent information flows and sharing, which improves overall productivity. Cloud based PLM enables automation of data operations and flows dynamically between the stakeholders.

Technology maturity, usability and usefulness were evaluated from a business benefit viewpoint. It can be concluded that maturity and usability are not yet quite good enough, but taking into account the current speed of development of such devices, they probably will be good enough, in the near future. However, this study was more of a proof-of-concept, which demonstrated the potential of contributing to business model innovation and game change, in an upgrade business. The tools and methods were not actually integrated with business processes and information management systems in production. Questions still remain as to what level of integration is needed between the tools and the IT systems for cost efficiency, and what kind of PLM information model development is needed. However, these 
aspects were kept in mind and carefully considered. In principle, there are no major technical obstacles for implementation and integration of the whole architecture. However, in addition to the technical issues, new processes and work methods may require an even greater effort.

This study has practical implications in industry and implications in PLM and engineering design research. This paper shows how novel technology can be utilized in industry and how it might enable business model innovations related to individual product upgrade services. However, this also requires a holistic and humanistic approach, taking into account processes, organizations, networks, leadership and ways of working. This paper contributes to research by discussing the closed-loop PLM concept, involving virtualization of PSS development and upgrading product individuals in MoL and EoL lifecycle phases. Connection to Product Avatars and the Industry4.0 concept was also discussed, from the perspective of the virtualization of product individuals and the enrichment of the digital 3D model, with knowledge from the middle and end of life phases. How VE and AR contribute to PLM was also discussed, in this context.

In a more philosophical way, the value of the UIW-approach can be explained with the notion of "Bounded Rationality" (Simon 1995). It means that human rationality is bounded by the very narrow focus of human attention. Because design is a process of searching, discovering the right goals, and finding information about constraints and available alternatives, it is highly valuable if we can extend the focus of designers and help then to see the right goals and choose the right alternatives. In the PLM and product development context, it must be understood that all stakeholders are also designers who not only contribute to the technical solution, but also to each other's success and well-being. This can also be understood with the shared value approach (Porter and Kramer 2011), which emphasizes a firm's opportunity to better utilize skills, resources, and management capabilities in order to better understand customers and mechanisms that influence productivity and success, both from economic growth and social progress perspectives.

Acknowledgements The research leading to these results has received funding from the European Community's Seventh Framework Programme under grant agreement No. 609027 (Project UIW). We want to express our gratitude to all colleagues and partners in UIW, especially for people of VTT, Metso Minerals, and RDVelho.

\section{References}

Ancona, M., Clini, P., Dellacasa, A., Falzone, P., La Camera, A., \& Quattrini, R. (2015). Extending a mobile device with low-cost $3 \mathrm{~d}$ modeling and building-scale mapping capabilities, for application in architecture and archaeology. In The International Archives of the Photogrammetry, Remote Sensing and Spatial Information Sciences (Vol. XL, pp. 25-27).

Aromaa, S., \& Väänänen, K. (2016). Suitability of virtual prototypes to support human factors/ergonomics evaluation during the design. Applied Ergonomics, 56, 11-18. 
Berglund, J., Lindskog, E., Johansson, B., Stahre, J., \& Vallhagen, J. (2013). Integration of 3D laser scanning into traditional DES project methodology. In Proceedings of the 2013 Winter Simulation Conference (pp. 4014-4015).

Berglund, J., Lindskog, E., Johansson, B., \& Vallhagen, J. (2014). Using 3D laser scanning to support discrete event simulation of production systems: Lessons learned. In Proceedings of the 2014 Winter Simulation Conference (pp. 2990-2999).

Bi, Z. M., \& Wang, L. (2010). Advances in 3D data acquisition and processing for industrial applications. Robotics and Computer Integrated Manufacturing, 26(5), 403-413.

Blessing, L. T. M., \& Chakrabarti, A. (2009). DRM, a design research methodology. London: Springer.

Bordegoni, M., Cugini, U., Caruso, G., \& Polistina, S. (2009). Mixed prototyping for product assessment: A reference framework. International Journal on Interactive Design and Manufacturing (IJIDeM), 3(3), 177-187.

Bosche, F., \& Haas, C. T. (2008). Automated retrieval of 3D CAD model objects in construction range images. Automation in Construction, 17, 499-512.

Brettel, M., Friederichsen, N., Keller, M., \& Rosenberg, M. (2014). How virtualization, decentralization and network building change the manufacturing landscape: An industry 4.0 perspective. International Journal of Mechanical, Aerospace, Industrial and Mechatronics Engineering, 8(1), 37-44.

Cavalieri, S., \& Pezzotta, G. (2012). Product-Service systems engineering: State of the art and research challenges. Computers in Industry, 63(4), 278-288.

Chryssolouris, G., Mavrikios, D., Fragos, D., \& Karabatsou, V. (2000). A virtual reality-based experimentation environment for the verification of human-related factors in assembly processes. Robotics and Computer Integrated Manufacturing, 16, 267-276.

Damgrave, R. G. J., Lutters, E., \& Drukker, J. W. (2014). Rationalizing virtual reality based on manufacturing paradigms. Procedia CIRP, 21, 264-269.

Dangelmaier, W., Fischer, M., Gausemeier, J., Grafe, M., Matysczok, C., \& Mueck, B. (2005). Virtual and augmented reality support for discrete manufacturing system simulation. Computers in Industry, 56, 371-383.

Di Gironimo, G., Lanzotti, A., \& Tarallo, A. (2014). A virtual reality framework for the design review of complex industrial assemblies: Case study on the interiors of superjet 100 aircraft. In I. Horváth \& Z. Rusak (Eds.), Proceedings of TMCE 2014, May 19-23, 2014, Budapest, Hungary (pp. 1553-1560).

Ellis, S. R. (1994). What are virtual environments? IEEE Computer Graphics and Applications, 14(1), 17-22.

Erdos, G., Nakano, T., \& Vancza, J. (2014). Adapting CAD models of complex engineering objects to measured point cloud data. CIRP Annals-Manufacturing Technology, 63, 157-160. doi:10.1016/j.cirp.2014.03.090.

Golparvar-Fard, M., Bohn, J., Teizer, J., Savarese, S., \& Peña-Mora, F. (2011). Evaluation of image-based modeling and laser scanning accuracy for emerging automated performance monitoring techniques. Automation in Construction, 20(8), 1143-1155.

Gomes de Sá, A., \& Zachmann, G. (1998). Integrating virtual reality for virtual prototyping. In Proceedings of DETC'98 1998 ASME Design Engineering Technical Conferences September 13-16, 1998, Atlanta, Georgia, USA.

Gomes de Sá, A., \& Zachmann, G. (1999). Virtual reality as a tool for verification of assembly and maintenance processes. Computers and Graphics, 23, 389-403.

Gonzalez-Aguilera, D., Pozo, S. Del, Lopez, G., \& Rodriguez-Gonzalvez, P. (2012). From point cloud to CAD models: Laser and optics geotechnology for the design of electrical substations. Optics \& Laser Technology, 44(5), 1384-1392.

Huet, G., Culley, S., McMahon, C., \& Fortin, C. (2007). Making sense of engineering design review activities. Artificial Intelligence for Engineering Design, Analysis and Manufacturing, 21, 243-265. 
Jun, H., Kiritsis, D., \& Xirouchakis, P. (2007). Research issues on closed-loop PLM. Computers in Industry, 58, 855-868.

Kolev, K., Tanskanen, P., Speciale, P., \& Pollefeys, M. (2014). Turning mobile phones into 3D scanners. In 2014 IEEE Conference on Computer Vision and Pattern Recognition (pp. 3946-3953).

Kumar, A., Jain, P. K., \& Pathak, P. M. (2012). Industrial application of point cloud/STL data for reverse engineering. In DAAAM International Scientific Book (pp. 445-462).

Leino, S.-P. (2015). Reframing the value of virtual prototyping Intermediary virtual prototypingThe evolving approach of virtual environments based virtual prototyping in the context of new product development and low volume production. Tampere University of Technology.

Lejon, E., \& Jeppsson, P. (2015). Integrating use phase information and virtual product representation to support Functional Products. Procedia CIRP, 38, 204-209.

Lindskog, E., Berglund, J., Vallhagen, J., \& Johansson, B. (2013). Visualization support for virtual redesign of manufacturing systems. Procedia CIRP, 7, 419-424.

Lindskog, E., Berglund, J., Vallhagen, J., \& Johansson, B. (2014). Lean based problem solving using 3D laser scanned visualizations of production systems. International Journal of Engineering Science and Innovative Technology, 3(3), 556-565.

McAloone, T. C., \& Andreasen, M. M. (2004). Design for utility, sustainability and societal virtues: Developing product service systems. In International Design Conference-Design 2004 (pp. 1-8).

Meža, S., Turk, Ž., \& Dolenc, M. (2015). Measuring the potential of augmented reality in civil engineering. Advances in Engineering Software, 90, 1-10.

Ottosson, S. (2002). Virtual reality in the product development process. Journal of Engineering Design, 13(January), 159-172.

Ovtcharova, J. G. (2010). Virtual engineering: Principles, methods and applications. In International Design Conference-DESIGN 2010 (pp. 1267-1274).

Porter, M. E., \& Kramer, M. R. (2011). The big idea: Creating shared value. Harvard Business Review, 89(1), 0001.

Shen, Y., Ong, S. K., \& Nee, A. Y. C. (2010). Augmented reality for collaborative product design and development. Design Studies, 31(2), 118-145. doi:10.1016/j.destud.2009.11.001.

Simon, H. A. (1995). Problem forming, problem finding, and problem solving in design. In Collen \& Gasparski (Eds.), Design and systems: General applications of methodology (Vol. 3, pp. 245-257). New Brunswick: Transaction Publishers.

Tangen, S. (2005). Demystifying productivity and performance. International Journal of Productivity and Performance Management, 54.

Tanskanen, P., Kolev, K., Meier, L., Camposeco, F., Saurer, O., \& Pollefeys, M. (2013). Live metric $3 \mathrm{~d}$ reconstruction on mobile phones. In Proceedings of the IEEE International Conference on Computer Vision (pp. 65-72).

Tuma, Z., Knoflicek, R., Tuma, J., Bradac, F., \& Blecha, P. (2014). The process simulation using by virtual reality. Procedia Engineering, 69, 1015-1020.

Verlinden, J., Horváth, I., \& Nam, T.-J. (2009). Recording augmented reality experiences to capture design reviews. International Journal on Interactive Design and Manufacturing (IJIDeM), 3(3), 189-200.

Wang, G. G. (2002). Definition and review of virtual prototyping. Journal of Computing and Information Science in Engineering, 2(3), 232.

Weidlich, D., Zickner, H., Riedel, T., Processes, P., \& Chemnitz, F. T. (2009). Real 3D geometry and motion data as a basis for virtual design and testing. In Proceedings of the 19th CIRP Design Conference (pp. 30-31).

Wiesner, S., Freitag, M., Westphal, I., \& Thoben, K. (2015). Interactions between service and product lifecycle management. Procedia CIRP, 30, 36-41.

Wilson, J. R., \& D’Cruz, M. (2006). Virtual and interactive environments for work of the future. International Journal of Human-Computer Studies, 64(3), 158-169. 
Woodward, C., \& Hakkarainen, M. (2011). Mobile mixed reality system for architectural and construction site visualization. INTECH Open Access Publisher.

Wuest, T. (2015). Current approaches with a focus on holistic information management in manufacturing. In Identifying Product and Process State Drivers in Manufacturing Systems Using Supervised Machine Learning (pp. 51-67).

Open Access This chapter is licensed under the terms of the Creative Commons Attribution-NonCommercial 4.0 International License (http://creativecommons.org/licenses/by-nc/ $4.0 /$ ), which permits any noncommercial use, sharing, adaptation, distribution and reproduction in any medium or format, as long as you give appropriate credit to the original author(s) and the source, provide a link to the Creative Commons license and indicate if changes were made.

The images or other third party material in this chapter are included in the chapter's Creative Commons license, unless indicated otherwise in a credit line to the material. If material is not included in the chapter's Creative Commons license and your intended use is not permitted by statutory regulation or exceeds the permitted use, you will need to obtain permission directly from the copyright holder. 